\title{
LACAN COM KRIPKE: O REAL EM JOGO NO NOME PRÓPRIO LIDO COMO UM DESIGNADOR RÍGIDO
}

\author{
Márcia Rosa \\ Psicóloga, doutora \\ em Literatura \\ Comparada \\ (UFMG), com \\ pós-doutorado \\ em Teoria \\ Psicanalítica \\ (UFRJ). Professora \\ na Pós-Graduação \\ em Psicologia \\ (UFMG), \\ psicanalista, \\ membro da \\ Escola Brasileira \\ de Psicanálise e \\ da Associação \\ Mundial de \\ Psicanálise.
}

UFMG, Belo Horizonte, MG, Brasil
RESUMO: Este estudo coteja a teoria do Nome Próprio concebido como designador rígido, formulada pelo lógico Saul Kripke, e a teoria de Jacques Lacan sobre o Nome Próprio lido como significante puro - um significante cujo enunciado, igualando-se à sua enunciação, não tem qualquer significação ou sentido. Trata-se de assinalar pontos de convergência e de divergência entre o real em jogo na teorização lacaniana do Nome-Próprio e a essência postulada por Kripke no referente do Nome-Próprio. Ao mencionar, ainda que de modo suscinto, a teorização lacaniana sobre a letra e a nominação através do sinthoma, possíveis implicações clínicas dessa interlocução são aventadas.

Palavras-chave: Nome próprio, designador rígido, significante puro.

ABSTRACT: Lacan with Kripke: the real taken into consideration in the proper name read as a rigid designator. This study compares data from the theory of the Proper Name conceived as a rigid designator formulated by the logician Saul Kripke and Jacques Lacan's theory on Proper Name as a pure signifier, a signifier whose utterance, matching its enunciation, has no meaning or sense. The study aims to highlight points of convergence and divergence between the real in the Lacanian theory of Proper Name and the essence postulated by Kripke in the Proper Name reference. By mentioning, even though in a succinct way, the Lacanian theorizing about the letter and the nomination through the sinthome, possible clinical implications of this dialogue are suggested.

Keywords: Proper name, rigid designator, pure signifier.

DOI - http://dx.doi.org/10.1590/S1516-14982015000100009 
E ste trabalho se propõe a evidenciar os pontos de convergência e de divergência entre a teoria do Nome Próprio concebido como um designador rígido, formulada pelo lógico de Princeton Saul Kripke (1970), e a teoria do psicanalista francês Jacques Lacan sobre o Nome Próprio como um significante puro, um significante cujo enunciado, igualando-se à sua enunciação, não tem qualquer significação ou sentido. Para tal, apresentaremos o texto Identidade e necessidade, de Kripke, e a teoria lacaniana do nome próprio como um significante puro.

Essa interlocução entre a psicanálise e a filosofia a respeito do nome próprio nos permite observar que, embora sejam campos distintos, e exatamente pelas suas especificidades, ambas iluminam zonas de sombra. Em vista disso, torna-se possível indagar, a partir da psicanálise, se algumas formulações lógicas não desconheceriam a função de real da letra, mas também se essas formulações psicanalíticas não estariam, de algum modo, determinadas pela Metafísica. Em todos os dois pontos é algo concernente ao real que, pela passagem por um campo extraterritorial, de repente se mostra e suscita questões.

O fato de o real — termo que em cada um dos campos ganha significação específica - poder ser tomado e esclarecido por diferentes perspectivas, isto não o ilumina completamente. Em que pese isso, o interesse de Saul Kripke para a teoria psicanalítica lacaniana deve-se ao fato de que a lógica e a formalização surgem aí mais além de um formalismo vazio. Ao tratar a questão do ser nomeado através do designador rígido, o lógico inglês nos permite enfatizar a pertinência de trazer à teorização do nome próprio em psicanálise a questão clínica de um ponto mais além da falta a ser, questão que nos coloca diante dos nomes de gozo, ou, em termos mais gerais, diante de questões relativas ao tratamento do campo do gozo, campo lacaniano por excelência.

\section{SAUL KRIPKE E O NOME PRÓPRIO COMO UM ‘DESIGNADOR RÍGIDO’1}

Depois das três conferências pronunciadas pelo lógico Saul Kripke no Colóquio Filosófico da Universidade de Princeton, em janeiro de 1970, ${ }^{2}$ a filosofia analítica contemporânea se viu forçada a reconsiderar as suas concepções acerca da identidade e da necessidade.

Como fica a questão da identidade se os termos de uma proposição forem nomes próprios: necessária ou contingente? Que as proposições de identidade

\footnotetext{
${ }^{1}$ Para os comentários sobre Kripke servir-me-ei do curso Tópicos especiais em lógica filosófica: identidade e necessidade em Saul Kripke, David Wiggins e Alvin Plantinga, ministrado pelo professor dr. Edgar da Rocha Marques no Departamento de Filosofia da UFMG em 2000. ${ }^{2}$ Conferências publicadas em Semantics of natural language, editadas por Donald Davidson e Gilbert Harman, Dordrecht, Reidel, 1972, p.253-335 e em Identity and individuation, editadas por Milton K. Munitz, New York University, 1971, p.135-164. Em 1972, a Harvard University Press, em Cambridge, Massachusetts publicou Naming and necessity.
} 
sejam consideradas necessárias faz com que a admissão de que existem proposições contingentes de identidade represente um problema para os lógicos. Entre essas proposições, temos 'Hesperus é Phosphorus', 'Cícero é Tully', e outras que se referem a descobertas científicas e não a uma necessidade lógica, tais como: 'calor é o movimento das partículas' e 'água é $\mathrm{H}_{2} \mathrm{O}$ '.

Em sua conferência de 1970, publicada com o título Identidade e necessidade (1977), ${ }^{3}$ Saul Kripke começa caracterizando os problemas filosóficos nos quais as proposições contingentes de identidade incorrem. Para alguns, a conclusão seria a de que sempre que a e b são nomes próprios, se a é b, é necessário que a seja b. Proposições de identidade entre nomes próprios têm que ser necessárias para que sejam verdadeiras. Para outros, e entre eles Quine, o paradigma da designação dos nomes próprios é o etiquetar. Neste contexto, ao tratarmos uma proposição tal como 'Hesperus é Phosphorus', observamos que se a descoberta de que o mesmo planeta (Vênus) foi etiquetado duas vezes conforme seu aparecimento vespertino (Hesperus) ou matutino (Phosphorus) é empírica, a proposição 'Hesperus é Phosphorus' teria que ser uma verdade empírica, necessariamente contingente. A descoberta de que se tratava do mesmo planeta é posterior e não implica um raciocínio a priori, nem tampouco que os nomes próprios sejam descrições.

Uma interrogação se impõe: os nomes próprios presentes aí são de fato nomes próprios? A contingência de que 'Hesperus é Phosphorus' leva ao fato de que a estrela que aparece em uma certa parte do céu à tarde é a estrela que aparece em uma certa parte do céu pela manhã; portanto, os termos Hesperus e Phosphorus podem ser considerados apenas abreviações para descrições, isto é, o termo Hesperus tem que designar "a estrela vista...", etc. Sendo assim, um lógico como Bertrand Russell propõe que esses nomes não são referenciais e nem simples etiquetas. Para ele, se queremos reservar o termo "nome" para coisas que nomeiam de fato um objeto sem descrevê-lo, os únicos nomes realmente próprios que podemos ter são os nomes de nossos próprios dados imediatos dos sentidos. Os únicos nomes como tais que ocorrem na linguagem são demonstrativos como este (this) e esta (that).

Torna-se fácil ver que esta exigência de uma necessidade de identidade, entendida como isentando as identidades entre nomes de toda e qualquer dúvida imaginária, pode ser garantida somente pelos nomes demonstrativos, pois só em tais casos uma proposição de identidade entre dois nomes diferentes pode ter imunidade contra a dúvida cartesiana. Sem nos estendermos mais sobre esse

\footnotetext{
${ }^{3}$ No decorrer deste trabalho nos referiremos, salvo indicação em contrário, ao capítulo assinado por Saul Kripke "Identity and necessity" do livro Naming, necessity and natural kinds, editado por Stephen P. Schwartz em London, Cornell University Press, 1977, p.66-102. Trata-se de uma republicação de Identity and individuation.
} 
ponto, anotaremos que Saul Kripke conclui dizendo que, por nome, ele quer mencionar não noções artificiais tais como a de Russell, mas um nome próprio no sentido comum (KRIPKE, 1977).

Uma vez feita esta caracterização inicial do problema, Kripke introduzirá — de modo surpreendente — a sua própria solução: "penso que em ambos os casos, o caso dos nomes e o caso de identificações teóricas, as proposições de identidade são necessárias e não contingentes" (idem, p.77). Depois de afirmar que os conceitos de a priori e de necessidade lidam com duas áreas diferentes, a Epistemologia e a Metafísica, Kripke formula a existência — paradoxal e absurda, à primeira vista — de proposições necessárias a posteriori, formulação sustentada em uma distinção entre o necessário que pode ser inserido no campo da Metafísica, na medida em que remete ao ser, e o a posteriori, que remete ao campo do conhecimento. Portanto, para o lógico de Princeton, uma proposição como 'Hesperus é Phosphorus' não seria contingente, mas necessária a posteriori.

\subsection{Identidade e necessidade a posteriori: o 'designador rígido'}

Para avaliarmos o escândalo representado pelas formulações kripkianas, é preciso mencionar a relação estabelecida até então pela filosofia entre necessidade e aprioricidade. Assim, antes de examinar a questão das identidades, retomaremos a noção de necessário em filosofia e, com Kripke, a distinção entre designador rígido e não rígido.

É interessante lembrar os três usos distintos que a noção de necessidade assume classicamente em filosofia: ${ }^{4}$ (1) Ao se referir à verdade, a necessidade nos conduz às proposições necessárias, isto é, proposições que são verdadeiras em todos os mundos possíveis, estando portanto blindadas contra a falsidade; neste sentido, necessário = verdadeiro. Por oposição temos as proposições contingentes, isto é, proposições cujo valor de verdade depende de circunstâncias, ou seja, elas podem ser falsas ou falsificadas, podem ser negadas. Se ‘ $2+3=5$ ’ é uma proposição necessária, seria contingente a proposição 'Sócrates é o mestre de Platão’. (2) Em outro uso, o termo necessário refere-se à existência e nos leva aos entes necessários; assim, ente necessário = ente existente. Ilustra-o a filosofia medieval para a qual a existência de Deus não depende de nenhuma condição especial, isto é, não há mundo possível no qual Deus não exista — ele existe de modo necessário, incondicional. (3) Em um terceiro uso, a noção de necessário refere-se à identidade: um ente possui necessariamente certas propriedades, isto é, não há mundo possível no qual ele não as possua. Desta forma, a noção

\footnotetext{
${ }^{4}$ Para estes comentários, feitos por minha conta e risco, refiro-me às aulas do prof. dr. Edgar da Rocha Marques.
} 
de necessário = essencial, ou seja, a determinação de identidade implica uma essência presente na coisa ela mesma, implica que se leve em conta as propriedades constitutivas do objeto. A noção de necessário relacionada à identidade nos levará mais tarde à questão da referência.

Cabe ainda salientar que partimos do fato estabelecido de que as proposições necessárias são proposições a priori, isto é, prescindem da experiência e, em vista disso, não são contamináveis pelo mundo empírico ou mesmo pela contingência. Ao apresentar a sua conferência no Colóquio de Princeton em 1970, Kripke afirma: “(...) eu não usarei aqui os termos ‘a priori’ e 'necessário’ de modo permutável” (KRIPKE, 1970/1972, p.260). Ao retomar a caracterização kantiana tradicional - "as verdades a priori são aquelas que podem (can) ser conhecidas independentemente de qualquer experiência" - Kripke interroga que tipo de possibilidade está em questão aí. Sem entrar em muitas considerações, ele afirma que alguns filósofos mudaram essa modalidade de tal modo que o possível (can) tornou-se o necessário (must). Portanto, é ao operar uma modalização — uma nova modalização - que o lógico de Princeton vai revolucionar: “(...) pode ser conhecido a priori não quer dizer deve ser conhecido a priori”, conclui ele (KRIPKE, 1970/1972, p.261).

Depois de dizer que os filósofos discutem as várias categorias da verdade — analiticidade, necessário e a priori — como identicamente sem significação e como permutáveis, Kripke mostra que a afirmação 'uma proposição necessária é verdadeira e não pode ser diferente’ pertence ao domínio da Metafísica. Por outro lado, quando se diz que 'uma verdade a priori pode ser conhecida independentemente da experiência', a verdade em questão surge do nosso conhecimento, ela independe da experiência de que algo seja verdade no mundo real. Assim, esta noção de a priori pertence ao domínio da Epistemologia. A conclusão de Kripke é a de que essas duas noções - de necessário e de verdade a priori — não são de modo algum a mesma; se são coextensivas, é preciso algum argumento filosófico para estabelecê-lo. Desse modo, para Kripke, o necessário nos remete ao fato de que dado que o mundo é como é, podemos interrogar como ele poderia ter sido (metafísica), e as verdades a priori nos remetem àquilo que pode ser conhecido do mundo real. Uma vez estabelecida a distinção entre os dois termos e entre os dois domínios, o lógico interroga: "tudo o que é necessário é cognoscível ou conhecido a priori?” (KRIPKE, 1977, p.85). Ainda segundo o autor,

"O ponto principal aí é que não é trivial que só porque tal proposição é necessária, ela poderá ser conhecida a priori. Alguns esclarecimentos consideráveis são requeridos antes de decidirmos que a proposição pode ser conhecida. Isto mostra então que, mesmo se qualquer coisa necessária é um a priori em um certo sentido, 
isso não deveria ser tido como uma simples questão de definição. É uma tese filosófica substantiva que requer algum trabalho.” (idem, p.86)

Posto isso, Kripke trata a distinção entre ‘designador rígido’ e 'não rígido'. Ele observa que 'a raiz quadrada de 25' designa necessariamente certo número, nomeadamente 5, e pode ser denominada 'um designador rígido'. Um designador rígido pode ser definido como "um termo que designa o mesmo objeto em todos os mundos possíveis” (KRIPKE, 1977, p.78). Não é difícil demonstrar, por tê-lo provado matematicamente e não empiricamente, que se trata de algo necessário.

Nas suas conferências de 1970, Kripke afirma que "um mundo possível é dado pelas condições descritivas que nós associamos a ele (...) Mundos possíveis são estipulados, e não descobertos por telescópios poderosos” (1972, p.267). Portanto, a noção de designador rígido não traz implícita a idéia de que o objeto ao qual se refere deve existir necessariamente e em todos os mundos possíveis. O autor continua:

“Tudo que eu quero dizer é que em qualquer mundo possível no qual o objeto em questão de fato existe, em qualquer situação na qual o objeto existisse, nós usamos o designador rígido em questão para designar aquele objeto. Em uma situação na qual o objeto não existe, então devemos dizer que o designador não tem referente e que o objeto em questão assim designado não existe.” (KRIPKE, 1977, p.79)

\subsection{0 retorno à questão da identidade ou a solução kripkiana}

Depois de ter introduzido a noção de 'designador rígido' e de ter feito uma distinção entre as noções de necessário e de a posteriori, Kripke retorna à questão da identidade, tal como surge na proposição 'Hespherus é Phosphorus', e afirma que não é preciso alinhar-se às soluções propostas por Quine ou mesmo por Russell. No seu entender, “certas proposições de identidade entre nomes, embora frequentemente conhecidas a posteriori, e talvez não cognoscíveis a priori, são de fato necessárias.” (1977, p.89) A sua conclusão é, pois, a de que

“se os nomes são designadores rígidos, então não pode haver dúvida sobre [o fato] das identidades serem necessárias, porque 'a' e 'b' serão designadores rígidos de um certo homem ou coisa x. Então, mesmo em cada mundo possível, 'a' e 'b' referir-se-ão ao mesmo objeto x, e a nenhum outro, portanto não haverá qualquer situação na qual 'a' poderia não ter sido 'b’. Esta seria uma situação na qual o objeto ao qual agora nós estamos também designando 'x' não teria sido 
idêntico a ele mesmo. Assim não poderia haver uma situação possível na qual (...) Hespherus não tivesse sido Phosphorus.” (KRIPKE, 1977, p.89)

Em resposta às objeções dos lógicos relativas à existência de uma identidade a posteriori, Kripke discute outra proposição de identidade na qual nomes próprios estão em jogo: 'Cícero é Tully'. Ao demonstrar que essa é uma proposição necessária, embora a posteriori, ele nos leva a discussões e conclusões fundamentais sobre a questão da fixação das referências e sobre as teorias do nome próprio existentes. No seu entender, se alguém usa o nome 'Tully' para referir-se ao orador romano que denunciou Catalina, e usa o nome ‘Cícero’ para se referir ao homem cujos trabalhos precisou estudar no colégio secundário, é claro que não pode saber com antecedência que o próprio homem que denunciou Catalina escreveu esses trabalhos - portanto, essa seria uma proposição contingente. Todavia, esse fato não deveria nos levar a pensar que a proposição 'Cícero é Tully', se é verdadeira - e de fato o é — , é contingente. Suponhamos, por exemplo, que Cícero realmente denunciou Catalina, mas achou que suas aquisições políticas tinham sido tão grandes que ele não necessitaria se incomodar em escrever quaisquer trabalhos literários. Diríamos que nessas circunstâncias ele não teria sido Cícero? Kripke responde que 'não’ e afirma que “em tais circunstâncias, Cícero não teria escrito quaisquer trabalhos literários” (1977, p.92). Não é uma propriedade necessária de Cícero que ele devesse ter escrito certos trabalhos. Podemos facilmente imaginar uma situação na qual Sheakespeare não teria escrito os trabalhos de Sheakespeare, ou uma na qual Cícero não teria escrito os trabalhos de Cícero. Ao levá-lo em conta, Kripke conclui que:

“o que pode ser o caso é que nós fixamos a referência do termo 'Cícero’ pelo uso de alguma frase descritiva tal como 'o autor desses trabalhos', entretanto uma vez fixada a referência passamos a usar o nome ‘Cícero' rigidamente para designar o homem a quem de fato identificamos pela sua autoria desses trabalhos. Nós não o usamos para designar quem quer que tenha escrito esses trabalhos no lugar de Cícero, se alguém os escreveu." (KRIPKE, 1977, p.92, grifos nossos)

Ao continuar a sua demonstração, Kripke diz que poderia dar-se o caso de que o homem que escreveu esses trabalhos tivesse sido Cassius e que ele não tivesse sido o homem que denunciou Catalina. Nesse caso, “não diríamos que Cícero teria sido Cassius, a menos que estivéssemos falando metaforicamente. Diríamos que Cícero, a quem nós podemos ter identificado e conhecido pelos seus trabalhos, não os escreveu, e que alguém, Cassius, por ex., os escreveu em seu lugar" (idem, p.93). 
Uma vez posto o problema da referência dos nomes próprios e levantado o problema de sua fixação, Kripke retorna à modalização recusando-se a tomar uma proposição como 'Cícero é Tully' no campo da contingência; ao tomá-la como tal estaríamos interpretando erroneamente a relação entre um nome e uma descrição usada para fixar a sua referência - estaríamos tomando-as como sinônimas. A propósito, ele mostra que, ao falarmos de "Cícero, a quem temos identificado pela propriedade contingente de que ele é o homem que de fato, isto é, no mundo real, escreveu certos trabalhos" (KRIPKE, 1977, p.93), há apenas uma ilusão de contingência, ou seja, a contingência apresenta-se aí apenas na fixação da referência.

Uma vez afirmada a necessidade da proposição, Kripke formula a sua própria posição com relação ao problema da referência e de sua fixação. Contrariamente aos mais recentes teóricos, ele diz acreditar que "a referência de nomes é raramente ou quase nunca fixada através de uma descrição” (idem, p.94). Ele diz não acreditar que seja uma família de propriedades que fixe a referência dos nomes. Assim, as propriedades não seriam usadas de modo algum para fixar as referências. Ao pressupor que metade das nomeações fossem fixadas por descrição, mesmo nesses casos, afirma ele, o nome não seria sinônimo de uma descrição, mas seria usado para nomear um objeto que selecionamos pelo fato de que ele satisfaz certa descrição. É por isso que, mesmo que Cícero não tivesse, por exemplo, escrito os trabalhos literários que escreveu, a identidade de Cícero permaneceria. ${ }^{5}$

\section{JACQUES LACAN E O NOME PRÓPRIO COMO UM 'SIGNIFICANTE PURO'}

Pode-se dizer que as formulações de Jacques Lacan quanto ao nome próprio antecipam, de algum modo, aquelas de Saul Kripke apresentadas em suas conferências Naming and necessity (1970). O encontro do psicanalista francês com a temática e as teorias do nome próprio dá-se justo no momento em que, percorrendo o tema das três identificações formuladas por Freud (a identificação ao pai, a identificação ao traço e a identificação histérica), aborda o $2^{\circ}$ modo: a identificação ao traço. Assim como as outras, essa segunda identificação é "parcial e extremamente limitada, tomando emprestado apenas um traço isolado da pessoa que é objeto dela" (FREUD, 1921/1976, p.135). Freud ilustra-a com uma paciente histérica que tossia como o pai - por este traço específico, a imitação do sintoma, ela se identificava a ele.

\footnotetext{
${ }^{5}$ Nas suas conferências iniciais, Kripke se deterá mais minuciosamente na temática e na discussão das teorias do nome próprio. Em que pese ser este o tema em questão neste trabalho, optei por destacar a questão no contexto mais panorâmico das proposições necessárias a posteriori.
} 
No seu seminário $A$ identificação, realizado no início dos anos 1960, ao abordar essa identificação ao traço, Lacan afirma que, se é do objeto que o traço surge, é algo do objeto que o traço retém, justamente sua unicidade. Tal traço é designado por ele "traço unário" (einziger Zug), e através dele é abordada a função do Ideal do Eu. Ao sustentar, com Saussure, uma concepção de língua como um sistema de diferenças, o psicanalista concebe o traço unário como um elemento da bateria significante, elemento que é uma marca de pura diferença. Com essa noção retoma uma série de temas, tais como: o automatismo de repetição, a diferença dos fonemas o e a no jogo da criança com o carretel, o caçador contando os entalhes, a arte rupestre, a marca, a escritura e o nome próprio. Ao vincular a leitura do traço unário à designação da diferença, Lacan reafirma que o einziger Zug é o traço unário na medida em que toda a série se sustenta pela sua pura repetição. Trata-se do Um contável, visado em seu ponto inaugural, e não do um que conflui na ideia de totalidade.

É exatamente neste contexto (Lições de 20/12/1961 e 10/01/1962) que Lacan examina as teorias do nome próprio. À interrogação “o que é o nome próprio?”, interrogação cuja resposta ele diz não nos surgir a um primeiro exame, e surpreender quando surge, ele responde dizendo ter se deparado a propósito disso com a função do significante, sem dúvida em estado puro (Lição de 10/01/62). No entanto, antes de discutir essa afirmação, retoma a posição do lógico Bertrand Russell (1905) e as objeções feitas a ele pelo linguista e egiptólogo Allan Gardiner (1954).

Para Russell, agora com Lacan, haveria uma abordagem das coisas por uma descrição, e o modo de designá-las fora de toda descrição — isto é, como particulares - seria o nome próprio. Um nome próprio seria word for particular, concepção que acaba por levá-lo não apenas a afirmar o pronome demonstrativo "este" (this) como um nome próprio, como vimos, mas também a dizer, por exemplo, que Sócrates não é mais word for particular, pois, sendo descrito como 'mestre de Platão', ou 'o homem que bebeu a cicuta', faz-se dele uma descrição abreviada e ele deixa de ser uma palavra para designar o particular em sua particularidade. Ao comentar a teoria russelliana do nome próprio, Lacan assinala que todo o esforço secular da Lógica desemboca aí em um ponto de desconhecimento: "este desconhecimento é exatamente a relação mais radical do sujeito pensante com a letra” (Lição de 20/12/61). Seria isso, segundo o psicanalista, o que o linguista Gardiner, habituado a tratar com o hieróglifo e com o significante, objeta a Russell.

Gardiner apresenta o nome próprio como uma marca cujo caráter, não apenas identificatório, mas também distintivo, esforça-se em evidenciar: se algo é um nome próprio, é na medida em que não é o sentido do objeto o que ele leva consigo, porém algo da ordem de uma marca aplicada sobre o 
objeto, superposta a ele. Sem desconhecer a distinção entre o significante e o significado, o linguista, ao abordar o nome próprio, acentua o fato de que ele está composto de sons distintivos e não o fato de ter ou não um sentido. Ao tomar a dimensão significante veiculada na diferença sonora para caracterizar o nome próprio, Gardiner esbarra na constatação de que isso não é específico do nome próprio (uma vez que a própria linguagem está constituída de sons distintivos). Assim, não lhe resta outra saída senão a introdução do sujeito psicológico. Segundo Lacan, o fracasso de Gardiner deve-se à sua tentativa de articular a função do sujeito de outro modo que não por sua relação ao significante como tal.

\subsection{A função da letra (escritura) no tratamento psicanalítico do nome próprio}

Ao se servir da sua tematização da função do traço unário, Lacan diz que "não pode haver definição do nome próprio senão na medida em que percebemos a relação da emissão nominante com algo que, em sua natureza radical, é da ordem da letra" (Lição de 20/12/1961). Portanto, para tratar o nome próprio Lacan crê ser necessário fazer intervir na definição do inconsciente a função da letra, tal como ele diz ter feito nos seus textos $A$ instância da letra no inconsciente ou a razão desde Freud e $O$ seminário sobre $A$ carta roubada. Começa a se esboçar aí, em especial no segundo texto, a distinção entre o significante enquanto simbólico e a letra como pertencente ao registro do real, como um "significante puro", isto é, um significante que não porta nenhuma mensagem, que é sem significação e que não se insere na cadeia significante, reenviando a outros significantes, gerando efeitos de sentido ou de significação. Portanto, como significante puro, a letra fixa a referência, designando rigidamente.

A introdução da função da letra no tratamento do nome próprio conduz Lacan às questões do advento da escritura e, também, da relação da escritura à linguagem, que lhe surgiram a partir das objeções formuladas à sua teoria do nome próprio: pessoas que não sabem ler se servem dos nomes próprios, ou seja, os nomes próprios existem e determinam a identificação antes da aparição da escritura. Quanto a isso, o psicanalista (Lição de 20/12/1961) mostra que, desde que o homem é homem, possui não apenas uma emissão vocal como falante, mas também manifestações de traçados (como aqueles que aparecem nas costas dos antílopes ou nas paredes das cavernas) que, como o traço unário, são significantes e nada mais. Para o psicanalista, o importante é que algo da ordem deste traço funciona como distintivo e pode, conforme a ocasião, desempenhar o papel de marca.

A consequência a extrair daí, ainda segundo Lacan, não seria a da postulação da existência de uma arquiescritura — e aqui começam as diferenças, que acaba- 
rão sendo radicais, entre as formulações de Lacan e as do filósofo francês Jacques Derrida - , mas o fato de que a escritura aprende a funcionar como escritura na medida em que é vocalizada, fonetizada. O psicanalista afirma, então, que "todas as escrituras ideográficas, sem exceção, levam o traço da simultaneidade deste emprego que se denomina ideográfico, com o uso que se denomina fonético do mesmo material" (Lição de 20/12/1961). Em suma, o advento da escritura significa que algo que já é escritura — considerando-se aí os traços em sua função significante - chega a poder suportar esse famoso som, no qual Gardiner põe todo o acento no que concerne aos nomes próprios.

Lacan encontra uma confirmação de sua hipótese - a importância da letra no tratamento do nome próprio - no fato de que uma das características do nome próprio é

estar sempre mais ou menos ligado ao traço de sua união, não exatamente ao som, mas à escritura: "em todas as línguas Cleópatra é Cleópatra, Ptolomeu é Ptolomeu” (Lição de 20/12/1961). É surpreendente que Gardiner não se tenha lembrado que foi a partir da escritura desses dois nomes próprios que Champollion começou o deciframento dos hieróglifos. Lacan afirma que:

"o que distingue um nome próprio, apesar das pequenas aparências de acomodação — chama-se Köln’ a ‘Colonia’ - de uma língua a outra, é que de uma língua a outra isso se conserva em sua estrutura, sua estrutura sonora, sem dúvida, porém esta estrutura sonora distingue-se pelo fato da afinidade do nome próprio com a marca, com a designação direta do significante sobre o objeto.” (Lição de 20/12/1961, grifos nossos)

Não recairíamos aí na definição russelliana word for particular na medida em que Lacan pôde afirmar, a propósito deste sujeito instaurado pelo significante, ou melhor, pela letra, que "o sujeito só designa seu ser ao barrar tudo aquilo que ele significa” (LACAN, 1958/1998, p.700). Vemos surgir assim uma teoria lacaniana do nome próprio na qual ele é da ordem da letra e pertence ao registro do real. Ao funcionar como um significante puro, ele não tem qualquer significação ou sentido - "seu enunciado iguala-se a sua significação" (LACAN, 1960/1998, p.833). A sua característica fundamental estaria no fato de que não se traduz. O nome próprio se transpõe, se transfere, se translitera e, na medida em que não se traduz, leva o traço como marca do real (Lição de 10/01/1962).

Teremos então duas concepções da natureza do nome próprio:

“(...) uma (Frege, Russell) faz do nome próprio uma descrição definida, ou uma frase com um sentido (Sinn), pela qual é fixada sua referência (Bedeutung). A outra (Kripke, desenvolvendo as teses de John Stuart Mill) considera o nome próprio como um 'designador rígido' fixado de uma vez por todas por um 'ba- 
tismo inicial'. (...) A questão do seu sentido torna-se então secundária.” (MOREL, 1998, p.107)

Lacan incluir-se-ia nesta segunda concepção (o que não impede que, em outros momentos, ele opere com a primeira delas, interrogando, por exemplo, os efeitos de significação que um nome próprio pode produzir) quando situa o nome próprio como uma marca sobre o sujeito, como uma letra, quando afirma que:

“o nome (...) é uma marca já aberta à leitura, - eis por que ela será lida da mesma forma em todas as línguas - impressa sobre alguma coisa que pode ser um sujeito que vai falar, mas que não falará de modo algum obrigatoriamente. Prova disso é que Bertrand Russell se enganou quanto a isso, afirmando que se poderia chamar de John um ponto geométrico no quadro. (...) mas é bem certo que em nenhum momento ele interroga um ponto marcado com giz no quadro-negro na esperança de que o dito ponto lhe responda" (LACAN, 1963/2005, p.74)

Lacan enfatiza, portanto, que há no significante esse lado que está à espera da leitura e que é neste nível que se situa o nome, o nome do sujeito.

\subsection{Uma nova teoria da letra no tratamento psicanalítico do nome próprio}

Fazem parte da nova teoria da letra nos anos 1970 um aprofundamento da distinção entre o significante e a letra, entre os registros do simbólico e do real. Está em jogo, nas suas várias manifestações, outra concepção do inconsciente. Nesta virada, sensível no ensino de Lacan (Lição de 19/02/1974), as modalidades lógicas serão designadas por uma modalização que concerne à escritura:

o possível é o que cessa de se escrever (ocasionalmente não se escreve), o necessário é o que não cessa de se escrever (escreve-se sempre),

o contingente é o que cessa de não se escrever (ocasionalmente se escreve) e o impossível é o que não cessa de não se escrever (nunca se escreve)

Ao fazer essa modalização pela escritura, Lacan afirma que "o naming entanto que nome próprio precede, é um fato, a necessidade pela qual ele não vai mais cessar de se escrever" (LACAN, Lição de 11/12/1973). . Portanto, o nome próprio surge como algo que, sendo necessário (tal como em Kripke), é da mesma ordem do sintoma no seu estatuto de repetição, isto é, não cessa de se escrever,

\footnotetext{
${ }^{6}$ Teríamos uma alusão de Lacan ao Naming and necessity de Kripke?
} 
escreve-se sempre. Uma nuança na concepção do nome próprio apresenta-se aí: o nome próprio como sintoma, ou melhor, um sintoma pode funcionar como nome próprio do sujeito, como aquilo que designa repetidamente algo do seu ser e não cessa de se escrever, designação a posteriori se considerarmos que um sintoma é produto de uma construção ou invenção.

Na última parte de seu ensino — nos seminários R.S.I. e O sinthoma —, Lacan trabalha com a hipótese de que o sintoma poderia estabelecer uma nominação do sujeito. Depois de observar como a escritura funciona como um sinthoma para James Joyce e como, através dela, ele se faz um nome próprio, Lacan interroga se:

“não há nisso alguma coisa como uma compensação dessa demissão paterna, dessa Verwerfung de fato, (...)? (...) o nome próprio é, nele, alguma coisa estranha. (...) O nome que lhe é próprio, eis o que Joyce valoriza à custa do pai. Foi a esse nome que ele quis que fosse prestada a homenagem que ele mesmo recusou a quem quer que fosse." (LACAN, 1976/2007, p.86)

Na sequência do seu comentário, o psicanalista observa:

“É claro que foi uma invenção haver dois nomes que sejam próprios ao sujeito (...). Que Joyce também se chamasse James apenas se sucede ao uso do cognome — James Joyce, designado pelo cognome Dedalus.” (LACAN, 1976/2007, p.86)

Seguindo a pista dada por Lacan, de que o nome nunca aparece só, ele está sempre articulado, ao menos dois, encontramos na biografia de James Joyce as fontes do sobrenome Stephen Dédalos: o primeiro mártir cristão (Étienne) e o maior inventor do paganismo (Dédalos), assim "Stephen seria um santo da literatura (un saint home, un sinthome, e como Dédalos, ele inventaria asas para planar sobre seus compatriotas e um labirinto, uma arte misteriosa fundada sobre uma grande astúcia” (ELLMAN, 1987, p.182).

Eric Laurent (1998) observa que em Joyce o sobrenome é duplo também, ele anuncia os diferentes retratos do artista. Na medida em que alguma coisa no nome próprio “chama sempre um complemento" (LAURENT, 1998, p.3132), deparamos com a dimensão da referência e ela não cessa de se deslocar ao longo da sequência de nomes, sequência que abre assim o fracasso da referência. Laurent conclui, de modo bastante interessante, que "nosso campo admite, na perspectiva lacaniana, ao mesmo tempo o designador rígido e a abertura do buraco no sentido. Lacan indica aí um tipo de operação topológica: a cadeia do nome próprio entra no buraco que foi aberto" (idem). Essa operação do buraco no sentido que a nominação abre seria preenchida pela própria operação do nome próprio; nesse sentido, “preenche-se com um buraco”, ou, nos termos de 
Grigg, a casa vazia e a designação rígida colocar-se-iam em série (GRIGG, 1998). Seriam essas observações pertinentes para o caso de Joyce?

\section{PARA CONCLUIR}

Pode-se salientar ${ }^{7}$ que as formulações kripkianas estão marcadas por forte ideia de essência, de tal modo que as coisas pertencem aos tipos aos quais pertencem. Trata-se de um realismo de essências no qual existe uma essência, e ela é determinada por investigação (isto é, empiricamente), e não por uma investigação semântica. Existem, pois, características intrínsecas às coisas, isto é, opera-se aí com a noção de essência, de natureza, determinada não semanticamente.

Ao mostrar o limite das considerações semânticas, Kripke chegará ao campo ontológico, ou seja, ao problema do ser, e isto, como a identidade das essências não depende da sua apreensão, não depende da semântica. Essa questão surge na medida em que mais além dos mundos possíveis — mundos linguísticos ou semânticos - Kripke sustenta a existência de uma identidade transmundana, identidade designada de modo rígido. Trata-se, portanto, de evitar a ditadura semântica, ou seja, de evitar tomar os critérios de significação das palavras como critérios de identidade. Assim, o designador rígido explicitará a essência, isto é, o modo como a coisa é efetivamente, a coisa ela mesma. Se para Kripke o ser da coisa não deixa de estar determinado por um batismo inicial, que fixa a referência de uma vez por todas, entram em jogo aí critérios de mesmidade (de identidade) que são diferentes de critérios de reconhecimento, ou seja, critérios que se referem ao conjunto de representações dos quais é possível lançar mão para identificar um objeto — critérios, diga-se de passagem, contingentes.

As formulações kripkianas estão comprometidas também com a possibilidade de distinguir a necessidade metafísica e a necessidade lógica. Quanto a isso, nota-se que Kripke rompe com a noção analítica de necessidade — necessidade lógica - e defende a necessidade metafísica. “(...) aquilo com o que estou concernido aqui”, diz ele, “é uma noção [de necessidade] que não é uma noção de epistemologia, mas de metafísica, em um sentido não pejorativo (eu o espero)" (KRIPKE, 1972, p.261).

Se Kripke distingue o ser e o sentido do ser, ao tratar o nome próprio pelo significante puro, tomado enquanto letra na dimensão do real, a psicanálise se coloca do lado das teorias kripkianas da designação rígida. Portanto, não se trata de fixar a referência (Bedeutung) por meio de uma atribuição de sentido (Sinn) ao nome próprio. Lacan reafirma que "o sujeito só designa seu ser ao barrar tudo

\footnotetext{
${ }^{7}$ Para os comentários sobre Kripke neste ponto, feitos por minha conta e risco, sirvo-me das aulas do Prof. Dr. Edgar da Rocha Marques.
} 
aquilo que ele significa" (LACAN, 1958/1998, p.700). Qual concepção de ser está em jogo aí? A psicanálise também estaria marcada por um realismo de essências? Assim, ela é chamada a se pronunciar sobre as implicações metafísicas presentes na sua teorização do nome próprio.

Ali aonde a filosofia analítica se fundamenta em uma essência, no modo como a coisa é efetivamente, na coisa ela mesma, a psicanálise trata o real pela via da marca, da letra. Ao tratar o gozo pulsional pela via da escritura, concebida como uma operação de cifração e não de decifração (o que implica deixar de lado a atribuição de sentido), a psicanálise não cai no campo da metafísica, pois a dimensão de necessário do sintoma existe sob um fundo de impossível, ou seja, de algo que não cessa de não se escrever. Cabe lembrar que, a teoria lacaniana do nome próprio pressupõe o furo: um nome, por ser insubstituível, pode faltar (LACAN, Lição de 06.01.1965). Ele não deixa de remeter a "esse ser que aparece como que faltando no mar dos nomes próprios" (LACAN, 1958/1998, p.835) para que a bateria significante pudesse se completar, ser de gozo que a nominação não faz senão cifrar.

Para a psicanálise o sujeito e o ser se diferenciam permitindo-nos evocar este sujeito batizado inicialmente James Joyce, ao qual é necessário denominar Stephen Dedalus, um saint home, um sinthoma. Assim, um nome próprio, designador rígido do sujeito, dá lugar a uma nominação a posteriori (diferenciada do patronímico) que designa algo concernente ao ser do sujeito. Ao finalizar, reafirmamos que "a psicanálise se orienta pelo real e não pelo logos. Não fosse assim, e ela seria apenas mais uma ética”. ${ }^{8}$ É exatamente esse ser, esse real que o nome de gozo saint home não faz mais do que cifrar, que nos leva à ética da psicanálise.

Recebido em 10/8/2010. Aprovado em 3/9/2010.

${ }^{8}$ Comentário feito pelo psicanalista Márcio Peter de Souza. 


\section{REFERÊNCIAS}

ELLMANN, R. (1987) Joyce. Paris: Gallimard.

FREUD, S. (1976) Edição standard brasileira das obras psicológicas completas de Sigmund Freud. Rio de Janeiro: Imago.

(1921) “Identificação”, v. XVIII, p.133-139.

GRIGG, R. (1998) Le nom propre, clest le signifiant à l'état pur. Les maladies du nom propre, La cause freudienne, Revue de Psychanalyse, n.39. Paris: Navarin Seuil, p.125-129.

LACAN, J. (1961/1962) O Seminário, livro 9. A identificação. Inédito

"Lição de 20/12/61"; "Lição de 10/01/62".

(1998) Escritos, Rio de Janeiro: J.Z.E.

(1958) “A significação do falo”, p.692-703.

(1960) "Subversão do sujeito e dialética do desejo no inconsciente freudiano”, p.807-842.

(1963/2005) Nomes-do-Pai. Rio de Janeiro: J.Z.E.

(1965) Problemas cruciais para a psicanálise. Inédito.

(1973/1974) O Seminário, livro 21, Les non-dupes errent. Inédito

"Lição de 19/02/74"; "Lição de 11/12/73".

(2007) O Seminário, livro 23, O sinthome. Rio de Janeiro: JZE. “Joyce era louco?", p.75-87.

LAURENT, E. (1998) Symptôme et nom propre. Les maladies du nom propre, La cause freudienne, Revue de Psychanalyse, n.39. Paris: Navarin Seuil, p.19-34.

MARQUES, E. R. (1999) Putnam e a possibilidade de determinação de essências a partir de critérios semânticos. Síntese Nova Fase, Belo Horizonte, v. 26, n. 84, p.107-118.

MilleR, J. A. (1992) Comentário del Seminario inexistente. Buenos Aires, Manantial.

MOREL, G. (1998) Le symptôme en une phrase. Les maladies du nom propre. La cause freudienne, Revue de Psychanalyse, n. 39. Paris: Navarin Seuil, p.102-107.

KRIPKE, S. (1971) "Identity and Necessity", in MUNITZ, M.K. (Ed.), Identity and Individuation, New York University, p.135-164.

(1972) "Naming and Necessity", in DAVIDSON, D., HARMAN, G., (Eds.). Semantics of natural language. Dordrecht: Reidel, p.253-335.

KRIPKE, S. (1972). Naming and Necessity. Cambridge, Massachusetts: Harvard University Press.

(1977) "Identity and Necessity", in SCHWARTZ, S. P (Ed.) Naming, Necessity and Natural Kinds. London, Cornell University Press.

Márcia Rosa

marcia.rosa@globo.com 